\title{
Rank Offence: The Ecological Theory of Resentment
}

\author{
Samuel Reis-Dennis \\ Alden March Bioethics Institute, Albany Medical College, United States of America \\ reisdes@amc.edu
}

I argue that fitting resentment tracks unacceptable 'ecological' imbalances in relative social strength between victims and perpetrators that arise from violations of legitimate moral expectations. It does not respond purely, or even primarily, to offenders' attitudes, and its proper targets need not be fully developed moral agents. It characteristically involves a wish for the restoration of social equilibrium rather than a demand for moral recognition or good will. To illuminate these contentions, I focus on cases that I believe demonstrate a corollary thesis, namely, that strength, broadly construed, is a necessary condition of resentmentworthiness. I argue that weakness can make resentment unfitting in two ways. First, weakness may prevent a wrongdoer from shifting the balance of social power. Second, a weak wrongdoer may do social damage but be so lowly that resentment, which would represent him as excessively strong, would be inapt. Finally, I consider how accepting the ecological view might affect our theorizing about moral responsibility and the ethics of blame.

\section{Introduction}

In 'Freedom and Resentment', P.F. Strawson (1962) famously encouraged philosophers to notice the importance of the participant reactive attitudes to our interpersonal relationships. Of these attitudes, he focused especially on resentment, a non-detached reaction of those offended and injured by actions that manifest an objectionable lack of good will. In the years that have followed, scores of theorists influenced by Strawson have seized upon this attitude, sometimes making claims about the connections between eligibility for resentment and the more abstract concept of 'moral responsibility'. Such theorists seem to hold that resentment-worthiness and morally responsible agency travel together, and that discerning the conditions of resentment-worthiness will reveal the conditions of moral responsibility. ${ }^{1}$

\footnotetext{
${ }^{1}$ For a thorough cataloguing of the various philosophers who have made versions of this claim, and an admirable effort to explain their approach, see Todd (2016).
} 
For Strawson, it was essential that the attitude he called 'resentment' be both instantly recognizable and recognizably vital to our interpersonal interactions as we know them. ${ }^{2}$ Indeed, he repeatedly directed readers to attend to "what it is actually like to be involved in ordinary inter-personal relationships, ranging from the most intimate to the most casual' (Strawson, p. 77). But for all Strawson's admonitions to consider the real-life experience of resentment, it seems to me that contemporary moral psychologists, including many Strawsonians, have failed to fully recognize its contours.

I do find resentment to be both familiar and significant, but I have come to think that it is less moralized than most contemporary theorists of the reactive attitudes, and Strawson himself, believe. In this paper, I argue that resentment does not respond purely, or even primarily, to other people's attitudes at all. Rather, it is about disturbances in what I will call the ecology of social power. Fitting resentment tracks unacceptable imbalances in relative social strength between victims and perpetrators that arise from violations of legitimate moral expectations. ${ }^{3}$

In defending this 'ecological' view of resentment's psychology, I begin by examining cases that I think demonstrate a corollary thesis, namely, that strength, broadly construed, is a necessary condition of resentment-worthiness. I will argue that weakness can make resentment unfitting in at least two ways. First, weakness may prevent a wrongdoer from creating the imbalances in social power that resentment tracks. Second, even when a weak wrongdoer does social damage, he may still be so pitiable or lowly that resentment, which represents its objects as excessively strong relative to its subjects, would be inapt.

I begin by concentrating on two kinds of weak agents: children and devastated adults, in $\$_{2}$ and $\$_{3}$ respectively. Then, in $\$_{4}$, I explain why

\footnotetext{
2 In her paper 'Tragedy and Resentment' (2018), Ulrika Carlsson argues that we should reconsider our understanding of resentment's scope, and calls attention to the pain we feel in response to the hurtful attitudes of others that do not violate moral prohibitions. (The pain of unrequited love is a paradigmatic example.) Although I agree that what Carlsson calls 'tragic resentment' is a reactive attitude, it is not clear to me that her discussion of it amounts to a rival account of the emotional response Strawson had in mind. And so, while I am cautiously optimistic that my analysis may shed light on at least some of the cases Carlsson considers, I follow Strawson in focusing on situations that involve disrespect, wrongdoing, or lack of good will. I discuss this further in $\$ 4$.

${ }^{3}$ For simplicity, I focus mostly on expectations of good will. In certain cases, however, I believe that good-willed agents who violate obligations may also be fitting objects of resentment. This thesis is not critical to my argument here, but I have defended it elsewhere (2018).
} 
violation of a legitimate moral expectation, despite not being what resentment is about, is a necessary condition of its fittingness. Finally, in $\$ 5$, I briefly consider how accepting the ecological view might affect our theorizing about both moral responsibility and the ethics of blame.

Throughout the paper, I discuss the feeling, as opposed to the expression, of resentment. And I am concerned not with the utility of feeling this attitude, but rather with the fit between one's resentment and the conditions that give rise to it. ${ }^{4}$ I will argue that the 'internal logic' of resentment responds to social strength to an extent that philosophers have not realized or admitted. My hope is that noticing the importance of social power to this central reactive attitude will improve our understanding of the ethics of blame and moral responsibility. Acceptance of the ecological theory would require us to reconsider the ethics of resentment, including the ways in which it is reflected in our institutions. Justification of an emotion that protests deficient quality of will might differ substantially from justification of an attitude that represents wrongdoers as excessively powerful. And because accepting the social power view implies disavowal of the conceptual link between agential capacity and susceptibility to fitting resentment, such acceptance would also force us to question a standard approach to theorizing about the nature of moral responsibility.

\section{Resentment of children}

Normally, it is unfitting for adults to resent children. But explanations of the inappropriateness of adult-child resentment vary. David Shoemaker (2015) has observed that although many responsibility theorists agree that:

children might have a poor quality of will in some sense (the sense generating mere recoils), [they] insist that [this sense] is not [the one] implicated in our responsibility responses and so is not the one relevant to the conditions for responsible agency, conditions which instead are drawn from these theorists' own favoured interpretations of 'will'. (p. 13, emphasis in original)

${ }^{4}$ I assume that the fittingness of an attitude depends on the accuracy of the representations and/or beliefs that partially constitute it. For background on 'fittingness' or 'appropriateness', see Goldie (2000). For discussion of fittingness in the context of contemporary debates about moral responsibility, see Nelkin (2016) and Shoemaker (2017). 
As a result, accounts of responsible agency that emphasize rationality point to children's immature reasoning faculties to explain the impropriety of resenting them; theories that stress the importance of expressing one's character point to children's incomplete personal development; and so on. I will not weigh in here on the dispute between these competing theories of responsibility. Instead, I will argue that these explanations all suffer from a common problem: they focus excessively on children's incomplete agency as opposed to their social weakness.

Imagine a grade school bully who menaces people who wear glasses by derisively referring to them as 'Grandpa'. It seems to me that the bully clearly demonstrates poor quality of will. This is why, if the bully's parents learned of his conduct, they would be rightly embarrassed, and might tell the bully, honestly, that his behaviour was shameful, mean, and cruel-thick terms of censure suitable for illwilled action.

Whether an adult 'victim' might fittingly resent the child on the basis of such behaviour, though, is another matter, and the fact that the bully expresses ill will is not enough to settle the question. While concern and disapproval, and perhaps, as Shoemaker writes, 'recoils', would be apt, resentment from adults would be misplaced.

Children, on the other hand, do resent each other in response to expressions of ill will. Not only that, these feelings seem fitting. Imagine the bully's victim feeling stirred by resentment and confronting his tormentor on the playground. As adults, how should we view such a reaction? One might attempt to explain away the bully's seeming resentment-worthiness in various ways. For example, one might claim that the resentment would not be fully rational because children are just learning how to engage in reactive behaviour, that they're only 'practising' for the real thing. But while it is true that children are still learning, fighting back against a schoolyard bully need not be mere practice. It is a significant moral interaction on its own terms. We know from observing children, from consuming literature and film, and from our own memories of growing up, that a child's fullblooded resentment in response to being bullied is often intelligible and apt. $^{5}$

\footnotetext{
${ }^{5}$ In discussing the examples in this section and the next, I reference pre-theoretical intuitions about fittingness that I believe are both intelligible and widely shared. My attempt to vindicate them proceeds via reflective equilibrium. In what follows, I show that the ecological view of resentment unifies and explains these impressions with a clarity and elegance that
} 
How can we explain this? One possible line, which Pamela Hieronymi suggests in her excellent paper 'Articulating an Uncompromising Forgiveness' (2001), is that resentment is fitting only when directed at one's 'moral peers'. She suggests that we resent on the basis of transgressions that persist as current threats, and that expressions of ill will from people who are not 'worth being upset by' fail to threaten in the relevant way. What we are rightly concerned about, what we must protest, are the wrongdoings of our moral peers. Their actions, she argues, imply evaluations of us. If we think such an evaluation is 'mistaken' or 'wrong', then it poses a threat, and we must protest it (Hieronymi, p. 549). Importantly, though, such behaviour must have an author whose evaluations are worth caring about. It must express the assessment of a 'legitimate member of the moral community who can be expected not to do such things' (p. 530).

For Hieronymi, one's status as a moral peer, being worth caring about, seems to be closely connected to one's status as a full moral agent with the capacity to respond to moral reasons. She writes: 'To disregard your evaluation is to disregard you. Respect for you as a fellow human being commits me to caring about your evaluation. I may, in the end, think your evaluation mistaken and wrong. If it is importantly wrong, then, so long as you continue in your standing as moral peer, I will protest it. It fails to pose a threat only if it concerns an unimportant matter or if you fall from the status of moral peer' (p. 549).

This idea seems promising as an explanation for the unfittingness of adult-child resentment. As Hieronmyi puts it: 'We rarely resent harms done to us by children or the psychologically infirm; their claims don't carry enough weight' (p. 547). The conclusion is true, but one must say more. The crucial question is why the evaluations of children and the psychologically infirm carry little weight.

One natural explanation is agential, by which I mean that it emphasizes the underdevelopment of the capacities that distinguish fully fledged moral reasoners from children and the psychologically infirm. A proponent of such an explanation might hold that we could not expect a person who could not properly respond to reasons, for

opposing conceptions of the attitude's fittingness cannot match. I will argue that in addition to our intuitions about the fittingness of child-child resentment and the unfittingness of resenting devastated adults, the social power view also explains the intuitions that give rise to the famous philosophical problem of moral luck, which I address in $\$ 4$, and the power dynamics of the apology ritual, which I address in $\$ 5$. I am grateful to an anonymous reviewer for encouraging me to make this explicit. 
example, to make sound evaluative judgments. As a result, such a person's judgments would not be worth taking seriously, and he would therefore not be a fitting target of resentment.

Perhaps this notion of moral peerhood could explain the seeming appropriateness of child-child resentment. After all, the bully's fellow children are his peers, and so it stands to reason that they would rightly feel threatened by his evaluations. This is true as far as it goes, but a theory that explained peerhood in terms of the capacities required for moral agency could not make sense of it. This is because the argument that children's insufficiently developed faculties of evaluation and judgment prevent them from threatening adults in the right way proves too much. If children are unresentable because of their lack of development, why should anyone feel threatened by their faulty evaluations? An account that appealed to capacities could not explain the fact that children fully take up the participant stance in their relationships with each other and seem to fittingly resent their peers' disrespectful behaviour.

Perhaps, at this point, one might reply that children should not take each other's evaluations seriously, and that child-child resentment is misplaced. There is a grain of truth in the first part of this response: we do hope that children do not take bullies' taunts to heart. Revealingly, though, we do not usually tell them that resentment of their tormentors is inapt. Indeed, doing so would sound strained. Outside the grip of theory, it seems entirely appropriate for gradeschool children, despite their parents' assurances that their bullies are immature and not worth listening to, to feel resentment toward their ill-willed classmates. And this is true even for children who know how silly their bullies' claims are.

This indicates that the reasonableness of child-child resentment is not based on the status of child victims as a bully's moral peers, but, rather, as his social peers. The reason a child bully's incomplete development fails to render him unresentable is that resentment responds to deviations from what its subject sees as an acceptable balance of social power. These ecological disturbances are often more direct, bodily, material, and social than the more abstract threats posed by disrespect or misevaluation, which are implied by a wrongdoer's judgments, which are in turn implied by his conduct. We distort the field when we too quickly gloss over the obvious point that some children wield substantial power over other children. What they do and say can have a great influence on a peer's de facto social status and well-being. Bullies can coax other classmates to gang up on their 
targets; they can be physically imposing and violent; they can be popular and 'cool', able to embarrass even relatively mature, 'rational' victims.

Child bullies do not enjoy such social power in the adult world, and so their claims, and their actions, lack force. Grade schoolers are not usually physically imposing enough to menace adult 'victims' and are not considered 'cool' or popular in a way that matters to adults. In general, only adults can conspire to ruin another adult's social life. ${ }^{6}$ Our social structures limit children's disruptive capabilities. Children are simply too weak to shift social power dynamics enough to give rise to fitting resentment.

These observations suggest two conclusions. The first, which I have already stressed, that a lack of social power, not moral power understood in terms of the capacities required for moral agency, is the crucial barrier to adult-child resentment. Children's lack of development is, of course, one of the reasons for their lack of relative social strength, but this is, in a way, a red herring. Their social weakness, which is informed not only by their unfledged rational-evaluative capacities and developing characters, but also by their small physical stature, their financial dependence on parents and guardians, their lack of knowledge, and a host of other factors, is what limits the amount of damage they can do, and thereby prevents them from being fitting targets of adults' resentment.

This point, about the connection between resentment-worthiness and actual damage done, leads to the second conclusion: resentment is not only, or even primarily, about the attitudes, evaluative claims, and judgments of moral reasoners, but rather the concrete social effects of ill will and wrongdoing. ' The ecology of social power is irreducibly practical: when a boss denies an employee a deserved promotion, it is not only the boss's indefensible attitude that the employee objects to; the deprivation of status and salary must be set aright as well. When the schoolboy victim stands up to his bully, it is not only the insult of being called 'Grandpa' that he protests; the loss of face before his

\footnotetext{
${ }^{6}$ Of course, there are exceptions, as we will see shortly.

7 The point is similar to T.M. Scanlon's (2008) contention that blame is based on the 'meaning' of an agent's blameworthy conduct. Scanlonian blame involves modification of one's relationship with the blamed agent, and Scanlon is right that such modification must vary depending on the blameworthy behaviour's social significance and not just the attitudes that the behaviour expresses. Here, I am arguing that resentment, which responds to imbalances in social power, also depends on meaning in this way.
} 
classmates must also be rectified. Resentment tracks one's sense that one's rightful position in the social order relative to the wrongdoer has been disturbed, and reflects a wish that equilibrium be restored. ${ }^{8}$ The strength of such feelings depends in large part on the social significance of both the victim's injuries and the wrongdoer's ill-gotten gains. ${ }^{9}$

Consideration of social lowering reveals a second barrier to fitting adult-child resentment: children are, in standard cases, too weak to be apt targets of attitudes that involve a desire for levelling. And so, to explain the unfittingness of adult-child resentment, we may point to two social-power-related phenomena that often work in tandem. First, an adult target of a child's insult may not feel resentment because the remark fails to resonate with his social peers. ${ }^{10}$ But, second, even children who do real damage may remain relatively powerless and therefore unresentable. Seeing them as excessively strong would involve a misperception.

Consider, for example, how we might feel toward a child who picked up a handgun and shot someone. The intuition that we may not resent him does not imply that the attitude's unfittingness is wholly due to his immature agential capacities. Rather, I suspect that when we envisage such a tragedy, we imagine the child's fear, confusion, guilt, and devastation. We may even consider his physical smallness and picture the unbearable weight of his action pressing upon him as he ages. Each of these factors, in addition to his incomplete development and understanding, contributes to his weakness, and focusing on them rightly mitigates our resentment, perhaps even to such an extent that the attitude dissolves entirely. ${ }^{11}$

But let us now consider another example, one featuring children who did wield excessive social power. During the 1692 Salem witch-

\footnotetext{
${ }^{8}$ I cannot specify what a justifiable 'equilibrium' would be in these examples, though that would be important work for another paper. Here, I am concerned not with the distribution of social power or the ethics of levelling, but rather with the psychology of resentment.

${ }^{9}$ Our concern with the balance of social power and status goes beyond self-protection. That someone else is able to get away with treating others badly, that she sees herself as, or in fact is, 'above the law', can also prompt resentment. Jeffrie Murphy (1998, 2005) is particularly insightful on this point.

${ }^{10}$ There is often a kind of solidarity among adults, who might participate in a consensus that a child's rude comment is immature, unserious, or even cute. This consensus helps to transform the remark into something less threatening.

${ }^{11}$ I will give a more detailed explanation of this form of unresentability in $\$_{3}$.
} 
hunting crisis, Betty Parris, age nine, and Abigail Williams, age eleven, the daughter and niece, respectively, of Reverend Samuel Parris, accused adult villagers of witchcraft. They began by targeting three of the lowest-status members of their community, including a woman named Tituba, a person enslaved in the Parris household, and went on to accuse over fifty people, most of them women. Among other episodes, Williams simulated fits and seizures, claimed to have witnessed blood-drinking rituals, and interrupted a town meeting to declare that she saw a woman named Martha Corey, an accused witch, sitting 'on a beam suckling her yellow bird betwixt her fingers!' (Lawson 1692, pp. 3-4). The girls 'knew that their stories would be believed. In their religious world, witchcraft accusations (particularly against women [...]) were credible and demanded action because they were so threatening' (Reis 1997, pp. 7-8). Many of the villagers the girls accused, including Martha Corey, were ultimately convicted and executed.

I believe that it would have been fitting for the accused and their families to resent both Williams and Parris, despite their ages. Of course, the victims would have also been justified in resenting, and feeling betrayed by, the adults who empowered the girls by putting such stock in the tales of children. It is true that we expect and demand more of adults, and that they can therefore let us down in ways children cannot. But this does not mean that it is unfitting to resent socially powerful children like Williams and Parris, who, in concert with adults, destroyed a community.

\section{Culpable unresentables}

In the previous section, I suggested that even when children behave badly enough to disrupt adults' lives, they are often too socially weak to be fitting targets of resentment. But the smallness, ignorance, and dependency of childhood is only one form of weakness among many. In this section, I explain how the point generalizes to adults as well. To make the case, I concentrate on devastated wrongdoers, people whom we might call culpable unresentables.

My discussion of these characters will make it clear that the concept of strength or power that I am working with is broad. While I cannot defend a fully developed theory of social power here, I hope that the following brief remarks, along with my analysis of the cases, will give readers a sense of what I have in mind. What we traditionally understand as a person's 'social status'-his influence, wealth, reputation, 
and so on-informs the strength (or weakness) that affects his resentability, but it does not exhaust it. A wide range of socially significant characteristics are also relevant, including emotional stability (or instability) and physical might (or frailty). Colloquially, we might say that anything that would bring a person 'high' or 'low' could influence what I am calling his social power or strength, and therefore his resentability. Features that make us targets of envy, admiration, fear, awe, reverence, and respect contribute to our strength; features that make us targets of pity, sympathy, condescension, and ridicule contribute to our weakness. ${ }^{12}$

Consider the contrast between the following cases. First, imagine a driver cruising down a winding road. Eager to meet a friend, he wants to pass a cyclist ahead of him. After waiting for a few minutes for a reasonable passing window, the driver loses patience and attempts the pass on a blind curve, only to have to swerve at the sight of an oncoming car. As he lurches back into his lane, his car clips the cyclist, who is lucky to escape the incident with only a totalled bike and some nasty abrasions.

Here, as in the case of the child bully who is resentable by his social peers on the basis of the real damage he is able to do to them, the cyclist's fitting resentment is not primarily about the 'claims' or attitudes the driver's recklessness implies. Though the cyclist may have concluded that the driver was selfish and showed insufficient care regardless of the incident's consequences, he might not have felt resentment as intensely, or at all, had he not been thrown from his bike. This difference in fitting feeling based on outcome is explained by the fact that resentment tracks social disequilibrium caused by poor quality of will rather than the quality of the wrongdoer's will itself. ${ }^{13}$

But now imagine a version of the example in which it is the driver who takes the worst of the collision, and suppose that the scraped-up cyclist, at first eager for a confrontation, finds the driver around the corner, thrown from his vehicle, covered in glass, and crying out in desperate agony for his mother as he bleeds out on the roadside. I contend that resentment in this case would be unfitting. To see someone in such a pitiable, wounded state as excessively powerful would be inapt.

\footnotetext{
${ }^{12}$ I am grateful to The Editors for encouraging me to make this explicit.

${ }^{13}$ I will discuss moral luck again in $\$ 4$.
} 
To be clear, the fact that the driver is too weak to be the target of an attitude that represents its objects as unduly strong is not due to a lowliness of status or rank. Possessing low social status is only one way in which a person might lack the relative strength necessary to be resentable. Because resentment is about social imbalances between victim and wrongdoer, anything that would mitigate disorder or unfair advantage - that would invalidate thoughts such as 'He can't get away with this' or 'Someone should put him in his place'-would fittingly assuage it. In addition to physical suffering, factors such as emotional devastation, fearfulness, and old age, for example, can also appropriately soften resentment toward weakened transgressors who enjoy lofty social positions. ${ }^{14}$

A sceptic might argue that resentment toward the driver would be fitting, but that it would be rightly overshadowed by feelings of pity or sympathy. This suggestion may seem initially promising: pity and resentment are indeed in tension here. But why should they be? What would explain why pity and resentment could not co-exist as do amusement and disgust, joy and relief, or even pity and contempt?

Rather than casting the conflict between resentment and pity as a senseless battle of brute forces, the ecological theory offers an 'articulate' explanation that comports with the widely shared intuitions about resentment toward and among children that I discussed in the previous section: pity represents its targets as weak, wounded, or lowly. Resentment, on the other hand, represents its objects as socially strong, or at least stronger than they ought to be relative to subjects, and involves a wish that they be humbled. Genuine objects of pity are not proper targets of this attitude. In his current state, the driver is so weak that seeing him as excessively powerful would be incorrect. ${ }^{15}$

To be clear, the point is not that actually lowering the driver would be morally wrong. Rather, it is that feeling resentment in this instance would amount to a perceptual failure: seeing a weak, wounded, suffering being as holding or expressing excessive social strength. ${ }^{16}$

${ }^{14}$ Of course, frailty and old age can affect one's social position as well.

${ }^{15}$ This kind of misperception could be the result of incomplete information, or might express vices such as spite, pettiness, or a stingy unwillingness to let anything thwart the collection of a social debt.

${ }^{16}$ When I took 'driver's ed' as a teenager, my instructor offered our class a technique to help us overcome feelings of 'road rage'. He invited us to imagine that the would-be object of our wrath was driving home from the hospital where he had just been diagnosed with a 


\section{What is resentment about?}

In discussing the foregoing examples, I have argued that strength is a necessary condition of resentment-worthiness. But the ecological theory of resentment consists in a stronger thesis that I have also been suggesting, namely that resentment 'is about' or 'tracks' perceived deviations from a normatively acceptable social balance between victim and perpetrator that result from wrongdoing or a lack of good will. This latter, more ambitious claim does not follow from the former. Social disruption could be a necessary condition of resentment's fittingness even if the attitude were about the quality of its object's will after all.

To show that resentment is about ecological disequilibrium, one need not establish that it would be a fitting response to actions that cause social disruption despite evincing no moral shortcoming. Such a demonstration would prove something much stronger: not only that resentment is not about quality of will, but that violation of a legitimate moral expectation is not even a necessary condition of its fittingness. In this section, I will argue that this conclusion would be an oversimplification. I will show that fitting resentment tracks deviations from normatively acceptable balances of social power, and that a lack of good will or wrongdoing is a necessary condition of its appropriateness. ${ }^{17}$

If this is correct, then we will not be able to determine whether resentment is primarily about moral deficiency or social disturbance by examining cases in which one of these two elements is absent. Eliminating either would render resentment unfitting. Instead, we must consider cases in which both are present, but in varying degrees. In that spirit, let us revisit the encounter between the driver and the cyclist and imagine one version of the case in which the cyclist escapes unscathed and another in which he suffers serious injuries. Intuitively, the cyclist might fittingly resent the driver in either scenario, but we would expect his resentment to be stronger in the latter case.

Not wishing to get bogged down in the history of philosophical attempts to confront the phenomenon of moral luck, I will make only

terminal illness. The exercise works on two levels. Of course, one might think that the driver, reeling from the news, was not fully culpable for his poor driving, but I think the wisdom of the strategy is deeper: one imagines the driver feeling scared, vulnerable, impotent, and small-as a fitting object of pity rather than resentment.

${ }^{17}$ I would like to thank two anonymous referees for comments that helped inform the arguments I present in this section. 
the pedestrian observation that those who hold that resentment is about quality of will must strain to accommodate or reject these intuitions. The ecological view, on the other hand, gracefully explains the widespread impression, reflected in both our everyday sensitivities and our formal institutions, that the social consequences of wrongdoing influence the strength of our fitting reactions.

But now imagine that the driver struck the cyclist deliberately in order to send a message about what happens to cyclists who use 'his' road. If this intention and motive would make stronger resentment fitting, as I think they would, isn't this evidence that resentment is about quality of will after all? I do not think so. I have been arguing that resentment is fitting when a lack of good will disrupts a normatively acceptable social balance. And I have stressed the ways in which social ecosystems are attuned to factors such as wealth, social influence, and physical size, that have nothing to do with quality of will. This, however, does not imply that social equilibria are insensitive to motives and intentions. Quality of will does tend to be inversely correlated with the strength of fitting resentment, but the relationship between the two is indirect. Bad motives intensify fitting resentment insofar as they throw social balances askew. It is one thing to be unluckily injured by another person's banal negligence, but quite another to be callously abused or cynically manipulated. Different kinds of wrongs rupture the social fabric in distinctive ways, and they alter the standing of both victims and perpetrators. This can be so even if the true quality of the wrongdoer's will never comes to light. Left uncontested, the driver's action, for example, transforms the cyclist into a man he can deliberately and even casually victimize without consequence-a pawn in a depraved fantasy. While the driver's motives are essential to this social mutation, it is the ecological shift that would explain the intensification of fitting resentment. ${ }^{18}$

If variations in quality of will can only explain changes in fitting resentment indirectly, how can we be sure that moral shortcoming is a necessary condition of fitting resentment, as I have claimed? Social imbalances, after all, can produce hostility even in the absence of poor quality of will. Imagine, for example, two friends hoping for their 'big breaks' as Hollywood screenwriters. One writes a brilliant but understated script and is ignored; the other pens a mediocre adaptation of a superhero comic that launches him to prominence and gives him the

\footnotetext{
${ }^{18}$ I am grateful to two anonymous reviewers who encouraged me to clarify this point.
} 
power to make or break his friend's career. It would be intelligible for the spurned screenwriter to envy his friend's success and despise his newfound dependence on his generosity. These feelings would make sense despite their target's faultlessness. Such hostility would represent its object as possessing excessive social power, but I think assimilating it with the resentment I have been discussing would be misguided.

To explain why, I must return to Strawson. I have been aiming to offer a competing account of the emotion Strawson was concerned with - an attitude that has occupied philosophers hoping to discover the conditions of responsible agency for the last half-century. Failure to distinguish the attitude Strawson sought to analyse from unconstrained envy or ressentiment would be distorting. ${ }^{19}$ Where we are ashamed to admit our feelings of envy and ressentiment, we see Strawsonian resentment as (at least potentially) virtuous and expressible. Indeed, its explicit association with quality of will and legitimate moral expectations lends it its respectability, dignity, and righteousness. According to the ecological view, fitting resentment responds to social disequilibrium resulting from wrongdoing or the expression of deficient quality of will. Eliminating this moralizing qualifier would render the attitude unrecognizable as the one Strawson highlighted for its central place in our moral and social lives.

But our insistence on distinguishing resentment from socially unacceptable forms of power-based anger and envy need not distract us from their connections. Our concern with status and strength is deeprooted and potentially destructive. The emotions that attend this fixation-envy, jealously, vengefulness, spite-require regulation. My hypothesis (I cannot fully defend it here) is that vengeful, envious anger is a psychological precursor of resentment. The imposition of a lack of good will or wrongdoing as a fittingness condition distinguishes righteous resentment from these more primitive feelings. This moralizing shift pasteurizes the hostility of powerlessness, enabling us to feel and express it safely and productively.

The development of the apology ritual as a means of resolving resentment is another significant aspect of this (partial) purification. Indeed, thirst for apology, and the recognition of wrongdoing it involves, can be so desperate that even the extreme weakening of an

\footnotetext{
${ }^{19}$ While inspired by Nietzsche's (1887) use of the term, my discussion of ressentiment is not meant to reflect a rigorous analysis of his development of the concept. In referencing ressentiment, I have in mind a vengeful attitude rooted in envy of its target's power.
} 
offender can leave some victims unsatisfied if it remains unquenched. How can the ecological view accommodate this observation?

First, it is worth distinguishing instances in which resentment persists despite extreme weakening of the offender, from cases in which such weakening eliminates resentment but leaves the victim unfulfilled. ${ }^{20}$ Cases of the former sort, in which extreme weakening fails to eliminate resentment, tend to involve very serious wrongdoing. Consider the ways in which a woman's resentment toward her brother might fade upon hearing of his cancer diagnosis: her resentment might entirely dissolve if it stemmed from his impatience during a recent family gathering; if it were rooted in a long history of abuse at his hands, however, it may not recede to the same degree. Insofar as resentment remains fitting in the latter case, it is explained by the ongoing traumatic effects of the violence, humiliation, degradation, or cruelty inflicted upon the victim. Some wrongs are so disempowering that even the devastation of the wrongdoer is insufficient to correct the social imbalances they cause. ${ }^{21}$

In some cases of this kind, good apologies resolve resentment when extreme weakening cannot. But this does not imply that resentment must involve a desire for moral recognition per se. Rather, the power of apology in such instances reflects the brilliance of the ritual's characteristic method of rectifying social imbalances. In apologizing, a wrongdoer both lowers himself-by uttering the humbling phrase 'I'm sorry', and by demonstrating the pain of his guilt and contrition-and raises his victim - by affirming the sufferer's status and empowering her to offer or withhold forgiveness. ${ }^{22}$ In some cases of dehumanizing cruelty and abuse, such affirmation can socially elevate victims, and therefore restore equilibrium, in a way that mere weakening of the wrongdoer cannot. ${ }^{23}$

${ }^{20}$ I am grateful to an anonymous reviewer for encouraging me to consider this phenomenon.

${ }^{21}$ It is worth noting that the level of resentment victims feel in response to such degradation will itself be a function of the social and personal damage done rather than a pure reflection of the quality of will expressed.

${ }^{22}$ For an illuminating exploration of the connections between guilt, apology, and suffering, see Morris (1971).

${ }^{23}$ Of course, there are cases in which even a good apology and extreme lowering of the victim are not enough to eliminate fitting resentment. These may be instances in which a victim has endured too much suffering, disempowerment, or humiliation for any combination of events to restore an acceptable balance of power. 
Now let us turn to the second sort of case, in which weakening of the wrongdoer eliminates resentment but leaves the victim unsatisfied. This scenario poses no problem for the ecological view. Some emotions can be rationally resolved in multiple ways. One may reasonably feel unsatisfied (and even embarrassed) after banishing fear by fleeing rather than fighting, or when envy dissolves because of a rival's demise rather than one's own ascent. Similarly, the fact that victims may feel underwhelmed or cheated when extreme weakening without recognition renders their abusers unresentable does not imply that their attitudes have been non-rationally eliminated. One lesson of culpable unresentability (recall the case of the bleeding driver, or of the woman who ceases to resent her impatient brother after he is diagnosed with cancer) is that resentment and the desire for recognition can come apart. Apology may be the most satisfying means of rationally resolving resentment, but it is not the only one.

Earlier, I explained why we must not under-moralize our account of resentment, but I suspect that some readers will fear that I have not moralized it enough. How can one be certain that the strength-based resentment I have been discussing is a competing conception of the attitude Strawson had in mind? ${ }^{24}$ Here, we must remind ourselves again of Strawson's ambitions. In 'Freedom and Resentment', Strawson did not aim to offer an idealization of an unrefined but dominant emotional response; he meant to capture an everyday reaction, the familiar feeling informing moral practices that 'do not merely exploit our natures, [but] express them' (p. 93). In discussing 'resentment', he sought to characterize an emotion that occupied a central place in our real-life moral interactions, an attitude instantly recognizable as a hallmark of actual relationships.

This emotion protects our sense of dignity and fairness, animates our interpersonal response to injury and disrespect, and finds expression in our formal and informal institutions. I have attempted to show how an 'ecological' understanding of it unites and elucidates widely shared intuitions and insights about our moral practices and behaviours. The social power view explains our responses to the ill will of children and weak adults, the power dynamics of the apology ritual, the ways in which outcomes shape our fitting reactions, and what it means to make victims 'whole', both interpersonally and legally. Some philosophers may wish that our characteristic response to wrongdoing

\footnotetext{
${ }^{24}$ Helpful comments from an anonymous reviewer prompted me to address this objection.
} 
consisted purely of a demand for the good will that all moral agents are owed, but the facts on the ground dash this sunny Kantian hope. Indeed, I think that this excessively moralized account of our psychology has bleached philosophical conversation about the ethics of blame and the metaphysics of responsibility.

\section{Conclusion}

By inviting us to attend to the reactive attitudes rather than the metaphysics of action, 'Freedom and Resentment' promised deliverance from the wearying quest to discover the properties of a free will. My impression, however, is that rather than calling off the search, the Strawsonian turn has merely repositioned the hunting party. In their attempts to illuminate the contours of resentment, Strawsonians have almost invariably identified resentability with the development and expression of rational agency. Perhaps yearning for the familiar ground of free will metaphysics, they have had to moralize resentment's psychology in order to pass off favoured conditions of freedom (reasons-responsiveness, rational control, self-expression, evaluative capacity, and so on) as central to its logic.

I have argued that this link between agency and resentmentworthiness snaps under the pressure of a psychologically realistic account of resentment. Indeed, I have claimed that the development and exercise of agential capacity are only relevant to resentmentworthiness insofar as they affect the balance of power between aggressors and victims. If true, this conclusion should call the Strawsonian strategy-the attempt to uncover general criteria of moral responsibility by identifying the conditions of fitting resentment-into question. Children, whose rational development is incomplete, may be apt targets of resentment; psychologically healthy adults may not be, despite their full culpability for genuine wrongdoing. If Strawsonians wish to carry their project through, they must forsake the a priori faith in the agency-resentability connection that has distorted their perception of the hostile reactive attitudes.

The ecological view also has significant implications for the ethics of blame. ${ }^{25}$ I imagine that some readers may object to the idea that social lowliness, weakness, frailty, old age, and so on, might prevent someone from being fittingly subject to the full array of reactive

\footnotetext{
${ }^{25}$ I have written more extensively about the ethics of feeling and expressing resentful anger elsewhere (2019).
} 
attitudes that characterize rich relationships with other human beings. Doesn't the ecological view imply, for instance, that oppressed people may find themselves properly exempted from resentment?

The answer is yes: the social power view does imply that marginalized people will sometimes be unresentable, and this state of affairs is indeed a threat to their dignity and self-respect. ${ }^{26}$ But the problem here is with our social systems rather than the psychology of resentment. To force ourselves, in the name of morality, to resent those who do no damage, or to see the weak as excessively powerful, would be to resent on the basis of considerations extraneous to those that determine the attitude's appropriateness.

As we proceed from moral psychology to ethics, however, we need not strive for unconditional equality of social strength. It is perfectly normal and appropriate for a person struggling to come to terms with the loss of a family member or a frightening medical prognosis to be (and seem) wounded, scared, and weak. And there is no shame in being an inexperienced, insecure child who depends on her parents for everything. We need not force ourselves to resent the lowly, to find a way to banish resentment altogether, or to achieve absolute equality of social strength. Rather, we must decide what ideals and arrangements of social power are defensible and strive to cultivate a more just ecosystem. ${ }^{27}$

\section{References}

Carlsson, Ulrika 2018, 'Tragedy and Resentment', in Mind, 127(508), 1169-1191.

Goldie, Peter 2000, The Emotions (New York: Oxford University Press).

\footnotetext{
${ }^{26}$ It also implies that we lose the ability to fittingly resent others as we gain social strength. Some such shifts are minor (a promotion at work may alter one's social power relative to a stranger only slightly, if at all), but others could be significant (imagine that the promotion makes the would-be resenter the CEO of an imperious corporation). I thank The Editors for prompting me to make this explicit.

${ }^{27}$ I am grateful for feedback I've received from Susan Wolf, Elizabeth Reis, Matthew Dennis, and Pamela Reis. And I thank the reviewers and The Editors who read the manuscript for Mind, as well as Tobias Fuchs, who commented on the paper at a meeting of the American Philosophical Association. I have also benefited from discussion of these ideas with Tom Hill, Doug MacLean, and Susan Sullivan. Most of all, I am grateful to Vida Yao, who has generously read and commented on many versions of this paper, and with whom I have discussed these arguments at length.
} 
Hieronymi, Pamela 2001, 'Articulating an Uncompromising Forgiveness', in Philosophy and Phenomenological Research, 62(3), 529-555.

Lawson, Deodat 1692, A Brief and True Narrative of Some Remarkable Passages Relating to Sundry Persons Afflicted by Witchcraft, in Salem Village: Which Happened from the Nineteenth of March, to the Fifth of April, 1692, accessed online via the Evans Early America Imprint Collection, (https://quod. lib.umich.edu/e/evans/).

Morris, Herbert 1971, 'Guilt and Suffering', in Philosophy East and West, 21(4), 419-434.

Murphy, Jeffrie 2005, Getting Even: Forgiveness and Its Limits (New York: Oxford University Press).

Murphy, Jeffrie, , \& Jean, Hampton 1988, Forgiveness and Mercy (Cambridge: Cambridge University Press).

Nelkin, Dana 2016, 'Accountability and Desert', in The Journal of Ethics, 20(1/3), 173-189.

Nietzsche, Friedrich 1887, On the Genealogy of Morality, Maudemarie Clark and Alan Swensen (trans.), (Indianapolis: Hackett, 1998).

Reis, Elizabeth 1997, Damned Women: Sinners and Witches in Puritan New England (Ithaca, N.Y.: Cornell University Press).

Reis-Dennis, Samuel 2018, 'Responsibility and the Shallow Self', in Philosophical Studies, 175, 483-501.

- 2019, 'Anger: Scary Good', in Australasian Journal of Philosophy, 97(3), 451-464.

Shoemaker, David 2015, Responsibility From the Margins (Oxford: Oxford University Press).

— 2017, 'Response-Dependent Responsibility; or, A Funny Thing Happened on the Way to Blame', in Philosophical Review, 126(4): 481-527.

Strawson, P.F. 1962, 'Freedom and Resentment', in Free Will, ed. G. Watson (New York: Oxford University Press), 72-93.

Todd, Patrick 2016, 'Strawson, Moral Responsibility, and the 'Order of Explanation': An Intervention', in Ethics, 127(1), 208-240. 